\title{
Gestión del derecho de alcabalas y conflictos por la representación corporativa: la transformación de la normatividad electoral del Consulado de México en el siglo XVII ${ }^{1}$
}

En el Consulado de la ciudad de México se agrupaban los mercaderes que controlaban la distribución interna de ultramarinos y financiaban la producción de los principales bienes que eran comercializados dentro y fuera del virreinato, entre los que se destaca la plata. Constituido en 1594 como tribunal y gremio mercantil, el Consulado estaba encabezado por un prior y dos cónsules que eran elegidos anualmente por la universidad de mercaderes. ${ }^{2}$ Los individuos que encabezaban el Consulado ejercían el arbitraje judicial, representaban a la corporación, promovían los intereses de sus miembros $\mathrm{y}$, cuando era requerido, desempeñaron otras funciones, como la administración del derecho de alcabalas que gravaba la circulación, la venta y el intercambio de bienes.

Con excepción de una breve etapa que siguió a la creación del Consulado, durante las primeras décadas del siglo XVII la elección del prior y los cónsules se llevó a cabo sin mayores contratiempos. Sin embargo, una vez que la corporación se hizo cargo de la gestión del derecho de alcabalas en el distrito de la ciudad de México, la autoridad virreinal empezó a intervenir para que se eligiera o se mantuviera en los oficios del Consulado a los individuos que garantizaban a la

1 Agradezco las sugerencias de los doctores Michel Bertrand y Bernd Hausberger y, de manera muy especial, los comentarios críticos del doctor Ernest Sánchez Santiró, los cuales me permitieron hacer importantes reformulaciones al presente trabajo. Asimismo reconozco el apoyo otorgado por el CONACYT al proyecto "Comercio y Consulados en Nueva España".

2 El término 'Universidad' refiere a "la Comunidad, junta ò Assamblea, en que están adscriptos muchos para algun fin, ò oficio" (Diccionario 1990 [1726-39], III [VI]: 392). 
Real Hacienda el pago de las rentas del ramo mencionado, por ser uno de los más redituables de la Nueva España. Esta situación dio lugar a la formación de dos facciones que compitieron por los cargos de representación del Consulado, cuando menos durante las décadas de 1650 y 1660.

El objetivo central del presente ensayo radica en mostrar la forma en que se transformó el sistema electoral del Consulado, debido a la necesidad del gobierno virreinal de mantener a la cabeza de la corporación a un grupo que pudiera asegurar el pago de la renta de alcabalas. Veremos cómo fue restringida la participación de la asamblea integrada por la universidad de mercaderes en el sufragio de los electores que votaban por los representantes de la corporación, mediante la modificación de las reglas electorales del Consulado que se incluyeron en la Recopilación de Leyes de los Reynos de Indias de 1681. En ésta, se dejó a cargo del prior y los cónsules la designación de los electores que habrían de elegir a sus sucesores, quedando como única prerrogativa de la asamblea electoral la sanción de dichos nombramientos.

\section{El procedimiento electoral del Consulado según sus ordenan- zas originales}

En la Edad Media la institución consular adquirió un conjunto de privilegios, entre los que se destaca la libertad para elegir a sus autoridades. Dichas prerrogativas fueron reconocidas por la monarquía hispana a fines del siglo XV y principios del XVI. No obstante, con el objeto de centralizar y controlar la administración de la justicia, la Corona se reservó los derechos de ratificar los nombramientos de priores y cónsules, aprobar las ordenanzas de los consulados y designar al juez de alzadas, ${ }^{3}$ ministro que supervisaba las elecciones y atendía las causas de apelación del tribunal mercantil. ${ }^{4}$

3 El monarca ejerció dichas atribuciones en los consulados que se establecieron con su autorización a partir de las últimas décadas del siglo XVI (Smith 1978 [1940]: 30-32; Basas Fernández 1963: 34, 35, 117).

4 En la Nueva España, el virrey nombraba anualmente juez de apelaciones al ministro de la Audiencia que tuviera mayor antigüedad; Autos del Consejo de Indias, Valladolid, 19 de junio de 1603 y 24 de julio de 1604. En: Ordenanzas 1636: f. 22r, 23r. 
En la corporación mercantil de la Nueva España se realizaban comicios indirectos, cuyo modelo se tomó del régimen de elección del Consulado de Sevilla. Las elecciones eran un acto colectivo que reafirmaba la cohesión de los mercaderes, la cual sustentaba los privilegios concedidos por la Corona a la corporación de la que formaban parte. A continuación describiremos la forma en que se realizaban las elecciones, de acuerdo con las ordenanzas originales del Consulado, elaboradas en 1597,5 y la documentación sobre algunos de los sufragios que se llevaron a cabo en los dos primeros tercios del siglo XVII. ${ }^{6}$

Cada dos años, el 2 de enero se difundían mediante pregones las condiciones establecidas para los mercaderes que quisieran votar y ser nombrados electores. ${ }^{7}$ Estos debían ser

hombres casados, ò viudos, ò de veinte y cinco años arriba, tratãtes [...]. Que tengan casa de por si en esta Ciudad [de México]. Que no sean extrageros [sic]. Ni criados de otras personas. Ni Escriuanos. Ni los que tuuieren tienda publica de sus officios. Ni los que tuuieren tienda de mercaderias de Castilla, China, y de las que se tratan, y hazen en esta Nueua España $[\ldots]$

a no ser que en ella se vendieran las "que por su cuenta, ò por encomienda les vinieren consignadas". 8

En la Pascua de Reyes la universidad de mercaderes celebraba una misa para rogar al Espíritu Santo que iluminara a los votantes. Al día siguiente, la asamblea integrada por los mercaderes que satisfacían los requisitos mencionados se reunía en la sala del Consulado y sufragaba

5 Dichas ordenanzas fueron autorizadas por el rey en 1604 y confirmadas por el mismo en 1607; Real cédula, Ventosilla, el 20 de octubre de 1604, ratificada en San Lorenzo, el 16 de agosto de 1607. En: Ordenanzas 1636: f. 24v.

6 Legajo de los recaudos y diligencias sobre las elecciones de prior, cónsules, diputados y electores desde el año de 1620 hasta el de 1626, AGNM, AHH, caja 791, exp. 7; Cuaderno de elecciones del Consulado de 1636 a 1666, AGNM, AHH, caja 664, exp. 32.

7 Los pregones se efectuaban a partir de las dos de la tarde "en la entrada de la calle de san [sic] Agustin, y en la de las calles de San Francisco, Santo Domingo, y Tacuba, donde es el comercio, y trato de los Mercaderes" (Ordenanzas 1636: núm. iii, f. 4v-5r).

8 Ordenanzas 1636: núm. iii, f. $5 \mathrm{v}$. El último requisito obedecía a la diferencia social que había entre los mercaderes, que trataban al por mayor con bienes procedentes de lugares remotos, y el pequeño comercio, que era considerado sórdido, porque quienes lo ejercían tenían una baja posición económica y realizaban trabajo manual (Molas Ribalta 1985: 46-47). 
por treinta electores, bajo la supervisión del juez de alzadas. ${ }^{9}$ El número de mercaderes que asistieron a las asambleas electorales en el siglo XVII fluctuó entre 242, que fueron registrados en 1598, y 177 que se consignaron en la junta de $1689 .{ }^{10}$ Es importante destacar la importancia de la asamblea de mercaderes, dado que ésta designaba a los electores que un día después votaban por el prior, dos cónsules y cinco diputados. ${ }^{11}$ Hasta donde sabemos, los nombramientos para los cargos de representación del Consulado recayeron la mayor parte de las veces en los mismos electores.

Podían ser nominados prior y cónsules quienes fueran

cargadores por si, ò sus encomenderos, en cãtidad de dos mil pesos cada año, 12 ayã cargado dos años antes que sean electos, y sean ricos, $\mathrm{y}$ abonados, en cantidad de mas de veinte mil ducados [equivalentes a 16.666 pesos], y de buena opinion, vida, y fama. ${ }^{13}$

No se podía elegir en el mismo año "a padre ni à hijo, ni à dos hermanos, ni à personas que se nombren juntas en vna compañia", y la reelección sólo estaba permitida cuando hubieran transcurrido dos años después de haberse ocupado el cargo en cuestión (Ordenanzas 1636: núm. vi, f. 6v).

La necesidad de que uno de los magistrados conociera los asuntos pendientes en el tribunal mercantil mostró la inconveniencia de cambiar cada año a los dos cónsules. En 1619 se estableció la diferencia entre el cónsul moderno y el antiguo y, a partir de entonces, se eligió anualmente al prior y al cónsul moderno, mientras que el cargo de cónsul antiguo era ocupado después de haber servido un año en el

9 El segundo año en que ejercían el cargo, los electores también votaban la jornada siguiente a la festividad de Reyes (Ordenanzas 1636: núm. iii-vi, f. 4v-7r).

10 El primer dato procede del conteo de los mercaderes que asistieron a la Junta del Consulado de 1598; AGNM, AHH, caja 213, exp. 11, f. 1r-3r. La segunda cifra la proporciona Hoberman (1991: 20).

11 Para realizar el sufragio debían reunirse cuando menos veinte electores, los cuales debían llevar "escritas en sus cedulas, las personas por quien han de votar" para mantener el secreto. En caso de empate, el juez de alzadas tenía voto de calidad (Ordenanzas 1636: núm. v, f. 6r).

12 Dicha suma era muy elevada, ya que a principios del siglo XVII los corregidores tenían un sueldo anual que fluctuaba entre 200 y 300 pesos, los jueces de la Audiencia percibían 3.000 pesos y los gobernadores militares 2.000 pesos (Hoberman 1991: 20, 53).

13 Auto del Consejo de Indias, Valladolid, 19 de junio de 1603. En: Ordenanzas 1636: f. $21 \mathrm{v}$. 
oficio. ${ }^{14}$ Esta modificación favoreció la continuidad en las labores del tribunal mercantil y dio estabilidad al gobierno del Consulado.

El procedimiento electoral del Consulado que comprendía dos grados de elección, el de la asamblea de mercaderes y el de los electores, emanaba de una concepción de la sociedad que buscaba mantener la estructura jerárquica de sus miembros. El sufragio en asamblea, además de reforzar el marco comunitario de la representación corporativa, legitimaba el poder de la élite; mientras que el voto de los electores aseguraba el control de los notables que se ubicaban en la cúspide de la pirámide integrada por los mercaderes miembros del Consulado de la ciudad de México.

Aun cuando los mercaderes daban su voto de manera individual, procedían de acuerdo con los grupos de interés a los que estaban vinculados, ${ }^{15}$ los cuales se integraban en función de redes de parentesco e intereses económicos. Todo indica que en la asamblea al designar a los electores, se concretaban los acuerdos a los que habían llegado los dirigentes de la corporación, a través de la negociación y el compromiso, con los diferentes grupos que formaban parte de la universidad de mercaderes.

\section{Problemas para recaudar las alcabalas}

Luego de un largo periodo de resistencia, en 1575 se impuso en la Nueva España el $2 \%$ de derecho de alcabala sobre la venta, trueque y circulación de mercancías (Valle Pavón 2002). Cerca de una década después, la ciudad demandó que se le concediera la gestión de la renta mediante el régimen de encabezamiento (Sánchez Bella 1990 [1968]: 219-220), a través del cual la monarquía cedía temporalmente sus derechos fiscales a los consejos municipales, que eran los representantes legales de los contribuyentes. Por su parte, el Cabildo se comprometía a pagar una cuota anual, menor al rendimiento del impuesto, ya que debía sostener el aparato de administración y vigilancia que re-

14 Real cédula del 27 de junio de 1625, que confirma la del 7 de junio de 1619 , AGNM, AHH, caja 599, exp. 8.

15 Como ha explicado Guerra (1999: 52, 57-58), en el Antiguo Régimen "el voto libre no es necesariamente un voto individualista, producto de una voluntad aislada. Inmersos en una red de vínculos sociales muy densos [...] el elector escoge con libertad aquellos que mejor representan a su grupo". 
quería la recaudación del gravamen (Valle Pavón 1997: 50-54, y 1999: 151-156).

La concesión real del cabezón mayor autorizó a la corporación municipal para administrar la recaudación de la alcabala en el distrito de la ciudad de México por un periodo de 15 años (1602 a 1617). El nuevo sistema recaudatorio modificó la naturaleza del impuesto, al quedar la tasa de imposición del $2 \%$ únicamente como referencia para establecer el monto de la renta anual que la ciudad debía pagar al real erario. Con el objeto de facilitar el cobro de la alcabala, el Cabildo subarrendó a los grupos de causantes la gestión de los diversos rubros que integraban el ramo, mediante el otorgamiento de cabezones menores. En esta forma, se trasladó a los contribuyentes la responsabilidad de obtener la carga tributaria, situación que redujo los riesgos de cobranza y los costos de recaudación (Valle Pavón 1997: 53-56 y 1999: 153-154).

El ejercicio privilegiado de la gestión del impuesto podía transformarse en un negocio sumamente rentable. ${ }^{16}$ En primer lugar, los administradores del cabezón mayor podían recargar las rentas de los cabezones menores que negociaban con otros grupos de causantes, lo que les permitía reducir la cuota que ellos mismos debían de pagar. En segundo lugar, contaban con una fuente de información exclusiva y detallada sobre la situación de los diferentes mercados, la cual les permitía reducir los costos de transacción (Ibarra 1999: 135-136). En consecuencia, la gestión de las alcabalas debió haber beneficiado grandemente a los regidores que se dedicaban a la producción mercantil de granos, ganado, azúcar, pulque y harina, entre otros bienes, los cuales tenían una gran demanda en la jurisdicción de la capital. ${ }^{17}$

En los tres primeros encabezamientos que tuvo a su cargo el consejo municipal, de 1602 a 1643, el Consulado se hizo cargo de los cabezones menores correspondientes a los ramos de la alcabala que pagaban sus miembros, los comerciantes de menor rango y los artesanos, con lo que se responsabilizó de satisfacer entre el $68 \%$ y el $58 \%$

16 En la Francia de los siglos XVI y XVII, los beneficios del arrendamiento de derechos reales eran superiores a los que ofrecía el negocio de los cambios (Molas Ribalta 1985: 27-28).

17 Acerca de las actividades económicas que realizaban los regidores del ayuntamiento de la ciudad de México en los siglos XVI y XVII, véanse Porras Muñoz (1982) y Pazos Pazos (1999: 335-377). 
de la renta que pagaba la ciudad (Valle Pavón 1997: 52-58, 65). Al igual que los regidores, los dirigentes del Consulado podían beneficiarse con rebajas en el pago del gravamen, a costa de los artesanos y los comerciantes menores, quienes se encontraban en una situación de dependencia respecto a los mercaderes. ${ }^{18}$ Asimismo, podían disponer de valiosa información con respecto a la situación del comercio, la cual, en el caso de los mercaderes adquiría una dimensión especial, por ser la ciudad de México el principal centro de redistribución de la Nueva España.

El consejo municipal atribuyó al Consulado los adeudos de los dos primeros cabezones y en la negociación del tercero se opuso a que participara en la recaudación, con el argumento de que imponía a sus miembros gravámenes menores e incrementaba la tarifa a los otros causantes para compensar los faltantes. No obstante, la corporación mercantil logró conservar el cabezón menor, debido a su habilidad para recaudar la alcabala y a la capacidad de sus dirigentes para otorgar considerables adelantos a cuenta de las rentas que debía pagar en el futuro (Hoberman 1991: 193, 208-209; Valle Pavón 1997: 59-61, 64-65).

El establecimiento del tercer cabezón alcabalatorio se dio cuando estaba en pleno auge la política belicista del conde-duque de Olivares, el valido de Felipe IV. Como consecuencia de la participación de la Corona en tres diferentes frentes -Holanda, Inglaterra y Francia-y del descenso de los ingresos americanos, la Real Hacienda enfrentaba serias dificultades financieras, situación que la llevó a declarar la bancarrota en 1627 (Lynch 1988: 99-111; Álvarez Nogal 1997: 26). En 1628 el virrey marqués de Cerralvo empezó a negociar en la Nueva España la aplicación del proyecto Unión de Armas, a través del cual se pretendía distribuir entre todos los miembros del Imperio los gastos militares y administrativos que pesaban sobre Castilla. De acuerdo con dicho proyecto, se asignaron al Perú 350.000 ducados y a la Nueva España 250.000 ducados, esta última equivalente a 343.750 pesos. Ambas contribuciones debían mantenerse durante quince años y serían aplicadas a la creación y sostenimiento de doce galeones, ocho de los

18 Sobre la forma en que los mercaderes habilitaban con dinero y mercancías a los artesanos, además de la manera en que les arrendaban los locales en los que trabajaban, véase Hoberman (1991: 129-131). 
cuales se incorporarían a la Armada del Atlántico norte que custodiaba Gibraltar y el Canal de la Mancha y los cuatro restantes se destinarían a proteger la Carrera de Indias, objetivo que adquirió carácter prioritario luego de que los holandeses tomaron la Flota de la Nueva España en 1628 (Israel 1980 [1975]: 181-182; Hoberman 1991: 197-198; Elliot 1990a [1986]: 251-254, 276-280).

Luego de prolongadas discusiones con el Cabildo para decidir de dónde se obtendrían los recursos extraordinarios requeridos para la Unión de Armas, el virrey decidió incrementar la tasa de alcabala del $2 \%$ al $4 \%$ y un real al precio de cada juego de naipes (Hoberman 1991: 197-198). En consecuencia, la renta del tercer cabezón alcabalatorio (1632-1646) se incrementó prácticamente al doble, pasando de 91.000 a 180.000 pesos. ${ }^{19}$ Inconformes con el aumento, los mercaderes recurrieron al contrabando y al fraude fiscal, situación que aunada al cierre del comercio con Perú, generó un faltante anual en la renta de alcabalas cercano a los 40.000 pesos, el cual, a fines de 1636, había dado lugar a un adeudo desproporcionado. ${ }^{20}$

A instancias del virrey marqués de Cadereita, en 1636 la Audiencia entabló pleito contra el Consulado por violar los términos del tercer cabezón. En el litigio se confirmaron los cargos que habían hecho los regidores desde 1632 y se denunció que cuarenta de los mercaderes de mayor caudal habían pagado una tasa menor al $0,5 \%$, cuando les correspondía una tarifa del $4 \%$ ó del $6 \%$, dependiendo del tipo de transacciones que hubieran realizado. ${ }^{21}$ En consecuencia, en 1637 se anuló el cabezón menor que tenía a su cargo el Consulado; sin embargo, éste apeló ante la Audiencia, continuó recaudando la alcabala mientras se realizaba el litigio y se negó a reconocer los adeudos del tercer cabezón (Smith 1948: 28; Guice 1952: 76-79; Hoberman 1991: 208-210).

Ante la amenaza holandesa en el Seno Mexicano y las islas de Barlovento, Felipe IV encomendó al marqués de Cadereita en 1635 la

19 Escritura que otorgó el Consulado y universidad de mercaderes a la ciudad de México para la prórroga del $3^{\circ}$ cabezón de las reales alcabalas por el tiempo y espacio de 15 años, 1632-1646. En: Documentos 1945: 15-16; véase también Smith (1948: 8).

20 Al parecer, en 1636 se había acumulado una deuda que ascendía a 171.286 pesos (Hoberman 1991: 199-200).

21 Sobre los diferentes tipos de alcabala, véase Valle Pavón (1997: 55-56). 
inmediata formación de una armada que protegiera la zona, la cual se integraría con cuatro galeones y un patache. Luego de intentar incrementar diversos gravámenes de manera infructuosa, el Cabildo vio como única alternativa un nuevo aumento de $2 \%$ al derecho de alcabala, el cual, unido al alza del almojarifazgo en un $1 \%$, debía proporcionar una renta anual de 200.000 pesos. Al parecer, en esta forma pudieron adquirirse los navíos pertrechados que en 1641 empezaron a custodiar las flotas de la Carrera de Indias, el Seno Mexicano y el mar de las islas de Barlovento. ${ }^{22}$

A partir de 1639 la tasa de referencia de la alcabala se elevó del $4 \%$ al $6 \%$, como consecuencia de lo cual, la renta del tercer cabezón se incrementó de 194.800 pesos a 254.800 pesos (Alvarado Morales 1979: 231-247; Hoberman 1991: 206-208). Sólo entonces, el Consulado decidió aceptar el auto de nulidad del cabezón menor que tenía a su cargo, muy probablemente como una forma de resistencia al nuevo aumento de la alcabala. En adelante, el Cabildo vio incrementarse de manera singular el adeudo de la renta, aun cuando emprendió notables esfuerzos por combatir el contrabando y el fraude fiscal. ${ }^{23}$ Según Juan de Palafox y Mendoza, "el crecimiento de las alcabalas ocasionó que valiese menos con seis este derecho, que lo que antes valía con cuatro". ${ }^{24}$

Tenemos un ejemplo de la forma en que los mercaderes del Consulado defraudaban el pago de la alcabala en el juicio que realizó el Cabildo contra Álvaro de Lorenzana, quien fue elector del Consulado de 1638 a 1651 y diputado en 1644. Lorenzana fue demandado por la ciudad en 1641, debido a que había pagado un monto de alcabala mu-

22 Relación del estado en que dejó el gobierno el marqués de Cadereyta, México, 6 de diciembre de 1641. En: Torre Villar 1991, I: 392-393, 395. Sobre la formación de la Armada de Barlovento y los problemas para sostenerla, véase: Informe del ilustrísimo señor, don Juan de Palafox, obispo de la Puebla, al excelentísimo señor conde de Salvatierra, virrey de esta Nueva España, 1642. En: Torre Villar 1991, I: 421-424; véase también Alvarado Morales (1979: 24-31, 231-233) y Hoberman (1991: 206-208).

23 El monto de la deuda pasó de cerca de 68.000 pesos en 1641 a 175.000 pesos en 1642 y llegó hasta 450.000 pesos en 1643 (Hoberman 1991: 200). Sobre las formas de contrabando a las que recurrían los mercaderes para evitar el pago de alcabala, véanse Hoberman (1991: 210) y Alvarado Morales (1979: 276-277 y apéndice 4: 363-367).

24 Informe de Juan de Palafox, obispo de Puebla, 1642. En: Torre Villar 1991, I: 420 . 
cho menor al que le correspondía con el argumento de que muchos de los bienes que había introducido a la ciudad no eran gravables: unos por ser de uso personal, otros por haber sido donados a un convento, y algunos más porque se habían vendido fuera de la jurisdicción de la ciudad de México (Hoberman 1991: 210).

Aunque el Cabildo ganó el juicio, se encontraba en una posición de desventaja frente a Lorenzana, quien, como otros miembros de la oligarquía mercantil, muy probablemente había otorgado favores a los oidores de la Audiencia con la intención de ser favorecido por ellos. ${ }^{25}$ De modo que en 1645, cuando la ciudad intentó rematar una de las propiedades de Lorenzana para saldar el débito que tenía con el ramo de alcabalas, la Audiencia ordenó que pagara únicamente la mitad del adeudo (Hoberman 1991: 210).

A pesar de que eran bien conocidas las prácticas fraudulentas en que incurría la administración del Consulado, éste garantizaba el pago de una importante proporción de la renta, la cual adquirió gran relevancia ante los requerimientos financieros generados por el combate de la rebelión de Cataluña, la expulsión del ejército francés de la península ibérica y el mantenimiento de la campaña contra los portugueses. Además, las demandas de la metrópoli debieron haberse incrementado luego de que en 1641 los diez buques que integraban la flota de la Nueva España fueron destrozados por un huracán (Lynch 1988: 142-162, 271-272).

En el informe que dejó Juan de Palafox y Mendoza a su sucesor, consideró de "poco inteligente" la decisión de haber pasado a la ciudad los rubros de la alcabala que administraba el Consulado y recomendó que se le devolvieran,

porque [la renta] estará más segura en personas tan abonadas y ricas como los que concurren en él, como porque se defraudaran menos los derechos corriendo por su mano, pues hace el repartimiento por el cómputo y conocimiento que tiene de los caudales. ${ }^{26}$

25 Los mercaderes más acaudalados otorgaban préstamos al virrey, así como a algunos jueces de la Audiencia y otros funcionarios y encubrían a los que realizaban transacciones mercantiles (Hoberman 1991: 178, 188-189).

26 Informe de Juan de Palafox, obispo de Puebla, 1642. En: Torre Villar 1991, I: 440 . 
Por tales razones, en las "Ordenanzas para la Contaduría de alcabalas, y contador dellas", escritas entre 1641 y $1643,{ }^{27}$ Palafox estableció que el "Consulado se admita en cualquier ocasión que se haya de hacer encabezamiento, de la misma manera en que son admitidas las ciudades". 28

En 1643 la gestión de las alcabalas por parte del Cabildo se encontraba en plena bancarrota, en gran medida debido a la resistencia de los miembros del Consulado a satisfacer el gravamen (Hoberman 1991: 200-214). De acuerdo con el virrey conde de Salvatierra, ya no se pagaban las deudas, ni la cuenta corriente del ramo, de modo que se había acumulado una deuda de 1.444 .000 pesos por concepto de las quiebras del cabezón y los montos que se debían satisfacer cuando no llegaran las flotas y las naos de China. ${ }^{29}$ El virrey hizo auditoria de las cuentas del Cabildo, separó los adeudos de éste y del Consulado ${ }^{30} \mathrm{y}$, tomando en cuenta que la ciudad no podía pagar la renta de los últimos años del tercer cabezón, así como las ordenanzas de Palafox, propuso "al Consulado y a toda la universidad de mercaderes" que se encargasen de lo que tan justamente era de su obligación, "pues sólo de ella se debía esperar la reducción". 31

El conde de Salvatierra entró en difíciles negociaciones con los representantes de la corporación mercantil, quienes sólo aceptaban hacerse cargo de la administración de la renta a condición de que se les exceptuara del pago de los débitos correspondientes a la falta de flotas y naos de China, las cuales habían disminuido en la medida en que se habían incrementado los enemigos del Imperio. El virrey se negó y para que aceptaran tuvo que advertir a los representantes del Consulado que recurriría a la justicia, por ser "el cuerpo de mercaderes el que había que dar saneamiento a esta renta". En septiembre de

\footnotetext{
27 Véase al respecto Sánchez Bella (1991, I: 317-337).

28 Ordenanzas para los cinco tribunales desta ciudad de México, BNM, ms. 2940.

29 Véase al respecto: Escritura que otorgó el Consulado y universidad de mercaderes a la ciudad de México para la prorroga del $3^{\circ}$ cabezón de las reales alcabalas por el tiempo y espacio de 15 años, 1632-1646, capítulo 5. En: Documentos 1945: 15-17.

30 Entre los de la ciudad se incluían los gremios y otras personas, así como los regidores, cobradores, ministros y fiadores.

31 Relación del virrey conde de Salvatierra al rey, México, 26 de febrero de 1645. En: Torre Villar 1991, I: 504-505.

32 Ibid.: 505-506.
} 
1644 el Consulado informó al monarca que se había hecho cargo de la administración los últimos tres años del tercer cabezón alcabalatorio, así como de los adeudos de la renta, los cuales ascendían a 876.060 pesos. $^{33}$

La corporación mercantil se comprometió a pagar 254.800 pesos por cada uno de los tres años que faltaban para que concluyera el tercer encabezamiento, además de otorgar una fianza de 70.000 pesos, muy superior a los 40.000 pesos que había proporcionado la ciudad en 1632 (Valle Pavón 1997: 75-77). En reconocimiento al compromiso que había adquirido el Consulado, Salvatierra intercedió ante el monarca para que le condonara parte de la deuda y reabriera el comercio con Perú. ${ }^{34}$ De esta forma, la administración de la renta de alcabala se transformó en un elemento de negociación imperial.

La gestión del cabezón mayor de las alcabalas libró a la universidad de mercaderes de las presiones y los conflictos con el ayuntamiento. Además, sus dirigentes pudieron disponer de un fondo que les permitió equilibrar las finanzas de la corporación, y volvieron a obtener beneficios de la gestión de la renta mencionada. Por una parte, nuevamente dispusieron de información privilegiada sobre la situación de los mercados en la Nueva España, la cual, como vimos, les permitió reducir los costos de transacción y, por otra, se hicieron acreedores de rebajas en el pago del gravamen, situación que, al parecer, dio lugar a que el Consulado contrajera una nueva deuda en los años finales del tercer cabezón alcabalatorio. ${ }^{35}$

Asimismo, debe tenerse en cuenta que los representantes de la corporación mercantil se beneficiaban por los méritos que confería la administración de la alcabala, que era uno de los ramos más redituables de la Real Hacienda de la Nueva España. Como ejemplo tenemos el caso de Pedro de Soto López, quien al inicio de 1645, el segundo año que fungió como cónsul, solicitó a la Corona que su hijo ocupara una de las canonjías vacantes en las catedrales de México o Tlaxcala,

33 El Consulado a S.M. sobre haberse encargado de la administración de las alcabalas, México, 13 de septiembre de 1644, AGI, Méx., leg. 322.

34 Relación del virrey conde de Salvatierra al rey, México, 26 de febrero de 1645. En: Torre Villar 1991, I: 506, 535.

35 En 1655, casi diez años después de haber concluido el tercer cabezón, el Consulado no había logrado saldar los adeudos del mismo, por lo que el virrey duque de Alburquerque mandó embargar los cuantiosos bienes que dejó a su muerte Simón de Haro, quien había sido prior en 1646 (Guijo 1953, II: 40). 
luego de destacar la dedicación que había puesto en la administración de las alcabalas. ${ }^{36}$

\section{Gestión de las alcabalas y negociaciones por los cargos del Consulado}

La importancia que tenía para la Hacienda novohispana la renta de alcabalas, llevó a Juan de Palafox y Mendoza a recomendar a su sucesor la conveniencia de "que se elijan cada año prior y cónsules que tengan alguna dilatación y amor al servicio de Su Majestad". Así, en 1645 tenemos documentada, por primera vez, la intervención del virrey conde de Salvatierra para que el prior Domingo de Barainca se mantuviera en el cargo un año más, con los argumentos de que favorecería el aumento del comercio, que había decaído por el cierre del tráfico con Perú, ${ }^{38}$ y de que la misma universidad de mercaderes lo había elegido un año antes para garantizar el buen manejo de las alcabalas. ${ }^{39}$ Entonces, los productos de la Hacienda novohispana seguían siendo demandados con urgencia para sostener los ejércitos que combatían en Cataluña y Portugal, campañas que llevaron a Felipe IV a comprometer los ingresos que percibiría hasta 1648, lo cual lo condujo a declarar la segunda bancarrota de su reinado en 1647 (Lynch 1988: 166-167; Álvarez Nogal 1997: 39-40).

Una vez que el Consulado se hizo cargo del cabezón mayor de la renta de alcabalas, los requisitos para ocupar los cargos de prior y cónsul relativos a mantenerse activos en el comercio oceánico y tener cualidades morales reconocidas, pasaron a segundo plano. En adelan-

36 Pedro de Soto López pide canonjía para su hijo, México, 27 de febrero de 1645, AGI, Méx., leg. 322. Soto López fue nombrado contador del Real Tribunal de la Inquisición en 1645, posiblemente, entre otras razones, por la experiencia y los méritos que contrajo como administrador de las alcabalas; Cuaderno de elecciones del Consulado de 1636 a 1666, AGNM, AHH, caja 664.

36 Mandamiento del virrey conde de Salvatierra, 6 de enero de 1645, AGNM, AHH, caja 664, exp. 32: Cuaderno de elecciones del Consulado de 1636 a 1666.

37 Informe de Juan de Palafox, obispo de Puebla, 1642. En: Torre Villar 1991, I: 443.

38 Barainca realizaba importantes transacciones con Filipinas; Documentos relativos al pago de almojarifazgo por las mercaderías procedentes de Filipinas 1643 y 1666, AGNM, AHH, caja 218, exp. 25.

39 Mandamiento del virrey conde de Salvatierra, 6 de enero de 1645, AGNM, AHH, caja 664, exp. 32: Cuadernos de elecciones del Consulado de 1636 a 1666. 
te, la riqueza y el giro elevado del mercader adquirieron mayor importancia, porque garantizaban que los sujetos elegidos hubieran articulado densas redes de negocios que aseguraban su influencia sobre importantes sectores de la comunidad mercantil y otros grupos de contribuyentes. Se buscaba elegir a los individuos que pudieran garantizar el cumplimiento de las obligaciones fiscales de los miembros de la corporación mercantil y el resto de los causantes.

El caso de Simón de Haro ilustra acerca de los requisitos para ocupar los oficios de representación del Consulado. Haro era uno de los principales mercaderes de la Casa de Moneda, cuya labor consistía en comprar plata en pasta al por mayor a otros mercaderes de la ciudad de México, los cuales solían ser beneficiarios del crédito que Haro otorgaba. ${ }^{40}$ De este tipo de relación puede deducirse la presión que Simón de Haro pudo haber ejercido para que los miembros del Consulado pagaran el derecho de alcabalas. Dichos mercaderes a su vez otorgaban crédito en dinero y mercancías a labradores, ganaderos, dueños de ingenios y obrajeros que vendían sus mercancías en la ciudad de México, así como a los artesanos y los comerciantes de menor rango de la capital, ${ }^{41}$ a quienes podían presionar para que cumplieran sus obligaciones fiscales.

En razón de la presión que podían ejercer Simón de Haro y los mercaderes vinculados a las redes de financiamiento que controlaba sobre los contribuyentes del derecho de alcabalas, dicho mercader fue electo prior en 1646, luego de haber desempeñado dicho cargo en 1640 y 1643 y el de cónsul en el bienio 1638-39, y fue nombrado prior, a pesar de que en 1644 había solicitado a la Corona no volver a ser electo o nombrado para los oficios del Consulado. ${ }^{42}$ Entre los argumentos que había planteado para apoyar su petición se destaca el de no ser "cargador", requisito que, como vimos, se exigía para desempeñar los oficios consulares, así como el mérito de haber generado a la

40 Respecto a los mercaderes de la Casa de Moneda y sus relaciones con otros mercaderes, véase Hoberman (1991: 76-92 y 1998: 71-79). En 1653, Simón de Haro afirmó que anualmente introducía a la Casa de Moneda 250.000 marcos (2.031.250 pesos), cifra que equivalía, aproximadamente, al $55 \%$ del promedio anual de la producción registrada en dicha década (ibid.: 76).

41 Véase al respecto: Relación del estado en que dejó el gobierno el marqués de Cerralvo, México, 17 de marzo de 1636. En: Torre Villar 1991, I: 368-369.

42 Haro, además, había sido elector de 1636 a 1653; Cuaderno de elecciones del Consulado de Nueva España, 1636 a 1666, AGNM, AHH, caja 664, exp. 32. 
Real Hacienda ingresos muy elevados "en el ministerio de comprar plata y meterla a labrar a la Casa de Moneda", y la dedicación que había puesto para cobrar la multa por 900.000 pesos que había impuesto el visitador Pedro de Quiroga y Moya, en 1636, por el contrabando de mercancías procedentes de Filipinas. ${ }^{43}$

Con el apoyo del conde de Salvatierra, en 1645 el Consulado mandó un comisionado a la Corte Real a fin de que negociara la concesión del cuarto cabezón alcabalatorio (Guice 1952: 52). Sin embargo, ante los requerimientos del real erario, cuyos aprietos darían lugar a la segunda suspensión de pagos de Felipe IV, en 1647, las autoridades de la metrópoli decidieron poner a remate dicho cabezón, situación que desató una fuerte competencia entre el Consulado y el Cabildo. Finalmente, la corporación mercantil obtuvo el encabezamiento de las alcabalas, gracias al adelanto de sumas elevadas y a su capacidad para recaudar el gravamen. ${ }^{44}$ De acuerdo con Louisa Schell Hoberman (1991: 212), la autoridad virreinal aceptó la administración corrupta del Consulado, consciente de que era el mejor medio para conseguir que sus miembros pagaran la alcabala.

En la contratación del cuarto cabezón alcabalatorio, el Consulado obtuvo una serie de ventajas que le permitieron ejercer un mayor control sobre la recaudación; ${ }^{45}$ no obstante, contrajo nuevos adeudos,

43 En marzo de 1645 se había dictado la cédula en la que se eximió a Simón de Haro de ocupar los oficios del Consulado, sin embargo, ésta no se aplicó, por lo que tuvo que emitirse la cédula del 27 de mayo de 1651 para que fuera exonerado de dicha carga; Cuaderno de elecciones del Consulado de Nueva España, 1636 a 1666; AGNM, AHH, caja 664, exp. 32. En este documento pueden verse otros méritos de Simón de Haro, relacionados con el financiamiento del gobierno virreinal, a los que pueden agregarse los que menciona Hoberman (1991: 177).

44 La corporación mercantil obtuvo el encabezamiento del ramo al ofrecer una fianza por 135.000 pesos, frente a los 100.000 pesos que propuso el ayuntamiento, y el pago inmediato de 50.000 pesos para el despacho de la flota, cantidades que se otorgaron a cuenta de la renta del primer año del arriendo, la cual ascendía a 270.275 pesos; $4^{\circ}$ cabezón, asiento, condiciones y remate que el Tribunal del Consulado de esta Nueva España, hizo a favor de las reales alcabalas, 1647-1661. En: Documentos 1945: f. 2r-3v, 6r. También Guice (1952: 83-87).

45 El Consulado fue autorizado para expedir guías a fin de controlar a los arrieros, carreteros y trajineros; se estableció que el pago del gravamen debía hacerse a la entrada de los productos a la ciudad, "sin aguardar su venta", y que quienes los recibieran estuvieran obligados a informar de sus ventas para que se cobrara el impuesto sobre la segunda transacción o, en su defecto, pagarán ellos mismos el impuesto. El tribunal mercantil obtuvo jurisdicción en primera instancia sobre las causas referentes a la cobranza de las alcabalas; se concedió a sus guardias "vara 
además de los que correspondían al tercer cabezón. Como veremos más adelante, esta situación condujo a la corporación mercantil a una seria confrontación con la autoridad virreinal.

Simón de Haro volvió a ser nombrado prior en 1650, y en 1651 el virrey Luis Enríquez de Guzmán ordenó que se mantuviera en el cargo durante un año más, por el conocimiento que tenía acerca de la administración de las alcabalas y porque garantizaba que se efectuara el repartimiento del gravamen "con toda igualdad". ${ }^{46}$ Es posible que en la decisión del virrey influyera la apremiante necesidad de caudales que seguía generando la reconquista de Cataluña. ${ }^{47}$ En 1652, a solicitud del prior Simón de Haro y del cónsul que pasaba de moderno a antiguo, el virrey mandó que Jerónimo de Aramburu permaneciera en el cargo de cónsul un tercer año, porque tenía "asegurada la Real Hacienda" con su experiencia y "gran inteligencia". 48

Todo parece indicar que el grupo encabezado por Simón de Haro dominó el Consulado hasta 1652. En el cuadro número 1 se registran los mercaderes que ocuparon los oficios de prior y cónsul en el periodo $1636-1652$, los cuales, muy probablemente, fueron los principales integrantes de dicho partido. Las negociaciones entre los dirigentes de la facción dominante y la autoridad virreinal habían generado buenos resultados; sin embargo, en 1653 se desató la competencia por dirigir el Consulado, conflicto que sólo pudo resolverse con el acceso de un nuevo grupo a los cargos de prior y cónsul. Luego de cinco años en que se agudizó la lucha electoral, este partido, cuyos líderes eran Jacinto Dávila Aguirre y Felipe Navarro y Atienza, logró mantenerse en

alta de la real justicia, sin que las ordinarias donde estuvieren se lo puedan impedir ni conocer de cosa que les toque", en tanto que estos, así como los cobradores y arrendatarios de la renta, fueron autorizados para portar armas; $4^{\circ}$ cabezón, asiento, condiciones y remate que el Tribunal del Consulado de esta Nueva España, hizo a favor de las reales alcabalas, 1647-1661. En: Documentos 1945: f. 6r$14 \mathrm{v}$.

46 Auto de las elecciones de prior y cónsul de 1651, AGNM, AHH, caja 664, exp. 32: Cuaderno de elecciones del Consulado de Nueva España, 1636 a 1666.

47 En 1651 la Corona incautó un millón de ducados de los caudales privados de Indias, medida que comprometió los ingresos del real erario hasta el año de 1655 (Lynch 1988: 169).

48 Auto de las elecciones de prior y cónsul de 1652, AGNM, AHH, caja 664, exp. 32: Cuaderno de elecciones del Consulado de Nueva España, 1636 a 1666. 


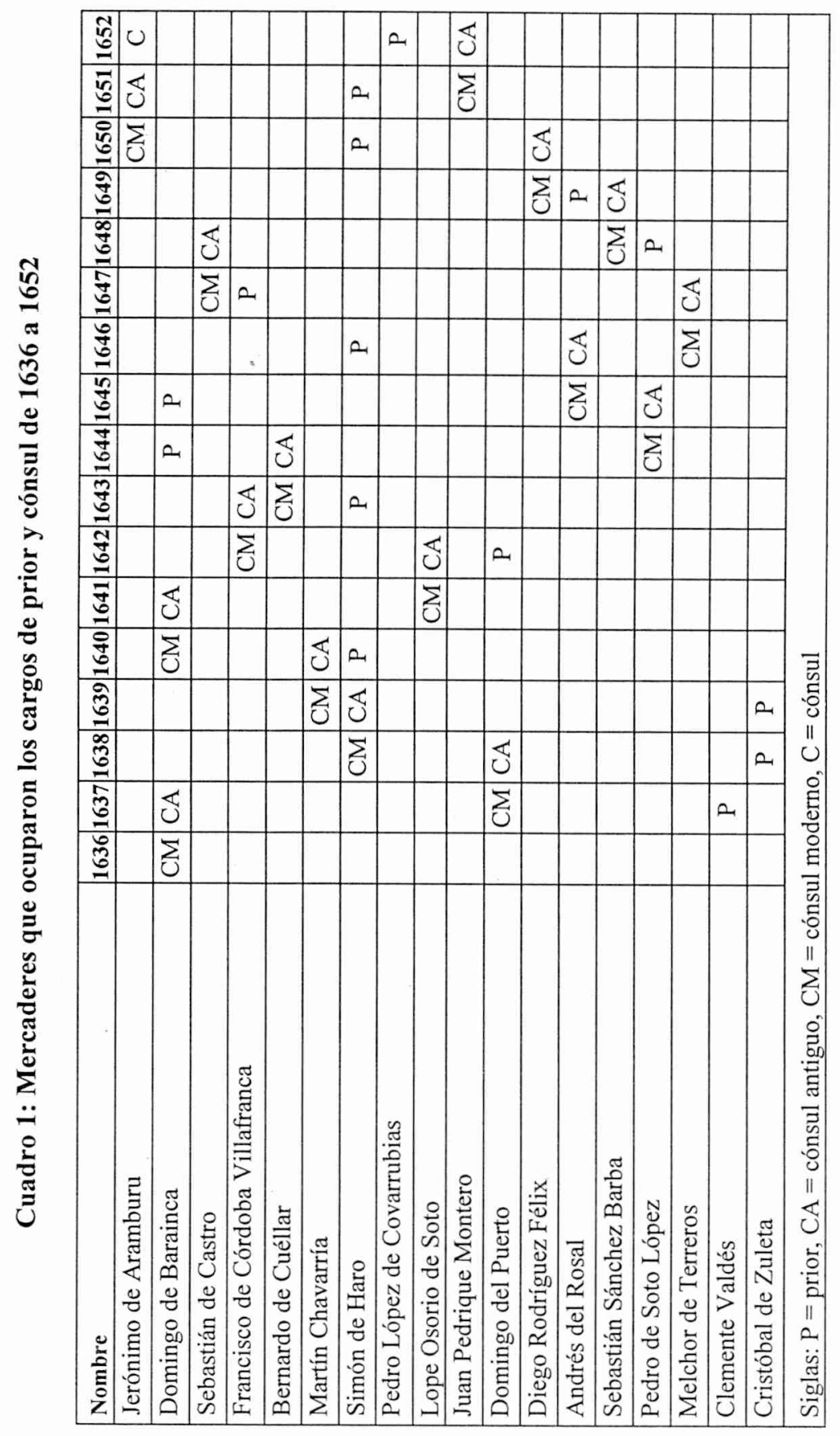




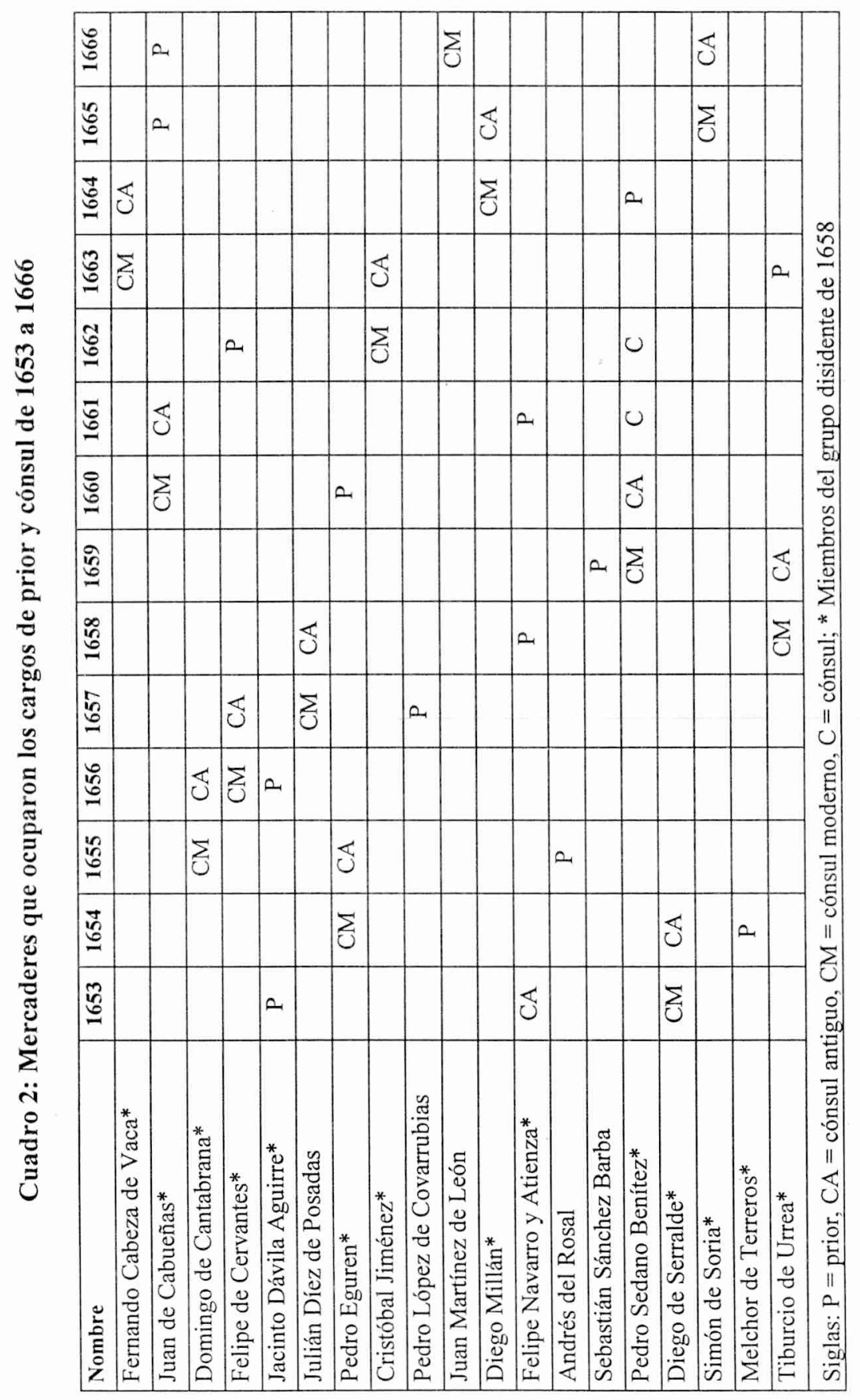


la cabeza del Consulado desde 1653 , hasta cuando menos $1666,{ }^{49}$ y sus miembros más destacados pudieron haber sido los mercaderes que ocuparon los oficios de prior y cónsul en dicho periodo, los cuales se incluyen en el cuadro número $2 .^{50}$

Poco antes de que se realizaran las elecciones de 1653, varios miembros de la corporación habían presentado al virrey Enríquez diversos candidatos para los cargos de prior y cónsul. Ante tal disyuntiva, el fiscal Pedro Melián dictaminó que Enríquez debía resolver la controversia, porque las funciones del Consulado no se limitaban a dirimir las causas entre mercaderes, ya que tenía a su cargo la gestión de "la renta más importante del virreinato". ${ }^{51}$ Además, ésta había adquirido mayor relevancia por el desequilibrio entre los gastos e ingresos de la Real Hacienda, el cual dio lugar a que en 1652 decretara Felipe IV una nueva suspensión de pagos (Lynch 1988: 169-170; Álvarez Nogal 1997: 44).

E1 fiscal planteó que el Consulado tenía que pagar al erario 270.275 pesos por la anualidad del ramo de alcabalas, motivo por el cual el virrey debía asegurar que se eligiera a las personas más idóneas para "la buena administración, cobro y seguridad de la hacienda real en tan crecida suma". Y sugirió que Enríquez de Guzmán consultara a los mercaderes "más desinteresados y celosos", a fin de que señalaran diez o doce personas "de las más ricas y abonadas en caudal y crédito y de mayor inteligencia, satisfacción y seguridad en el trato y procedimientos", para que los miembros del Consulado eligieran entre ellas a sus representantes. ${ }^{52}$

Los trece candidatos designados por el virrey no fueron del agrado de todos, ya que el día de los comicios algunos electores quisieron

49 El año de 1666 es el último para el que disponemos de información sobre las elecciones del Consulado.

50 En cuanto a los mercaderes que aparecen en los cuadros número 1 y 2, sólo sabemos que la facción que dominó en la primera etapa, en 1657 logró que se eligiera prior a Pedro López de Covarrubias y cónsul a Julián Diez de Posadas, no obstante, el año siguiente el partido contrario volvió a colocar a sus parciales en los oficios mencionados. Y suponemos que Melchor de Terreros cambió de partido, ya que aparece los ambos cuadros.

51 Auto de las elecciones de prior y cónsul de 1653, AGNM, AHH, caja 664, exp. 32: Cuaderno de elecciones del Consulado de Nueva España, 1636 a 1666.

52 El fiscal también propuso que no entraran en la elección quienes tuvieran adeudos de la renta de alcabalas. 
discutir la disposición; sin embargo, el juez de alzadas ordenó que votaran de acuerdo con el mandato del virrey. En esta forma, salieron electos prior Jacinto Dávila Aguirre, cónsul antiguo Felipe Navarro y Atienza y cónsul moderno Diego Serralde. ${ }^{53}$ Los sucesos relativos a las elecciones de 1653 muestran la capacidad negociadora de la nueva facción, cuyos líderes consiguieron que el virrey incluyera a cinco de sus parciales en la lista de candidatos para los cargos de representación y lograron convencer a la mayoría de los electores para que les dieran sus votos.

\section{Alianzas para asegurar la renta de alcabalas}

A la llegada del duque de Alburquerque a la Nueva España, en agosto de 1653, la situación del real erario era verdaderamente crítica. Luego de haber declarado la bancarrota en dos ocasiones, en un periodo menor a cinco años, Felipe IV se vio ante la imposibilidad de incrementar los ingresos reales, en tanto que su crédito se había deteriorado como consecuencia de la depresión del comercio americano (Lynch 1988: 170; Álvarez Nogal 1997: 44-45), el cual cayó dramáticamente a partir de $1650 .^{54}$ Es muy probable que la exigencia de caudales por parte de la Corona obligara al virrey a esforzarse por resolver los problemas del erario, entre los que se destacaban las deudas del ramo de alcabalas.

Alburquerque encontró la Real Hacienda empeñada en 1.200.000 pesos y tuvo que afrontar las quiebras del contador y los tesoreros del ramo de tributos, así como las crecidas deudas de los ramos de media anata, mesadas eclesiásticas y alcabalas. ${ }^{55}$ Decidido a regularizar la situación del erario, el duque pidió al visitador Pedro de Gálvez que

53 Los otros individuos nominados por el virrey eran Tiburcio de Urrea y Domingo de Cantabrana, quienes pertenecían a la misma facción que los mercaderes electos, Pedro López de Covarrubias, Francisco de Arellano, Juan Vásquez de Medina, Esteban de Molina, Franco Alfonso, Alonso de Valdés, Diego Muñoz de Sandoval y Francisco Sánchez de Cuenca. Autos de las elecciones de prior y cónsul de 1653, AGNM, AHH, caja 664, exp. 32: Cuaderno de elecciones del Consulado de Nueva España, 1636 a 1666.

54 Véase al respecto Lynch (1988: 262-269) y Romano (1993: 131-133, en especial las gráficas núm. IV.3 y IV.4).

55 Mandamiento del virrey duque de Alburquerque, México, 7 de enero de 1656, AGNM, AHH, caja 664, exp. 32: Cuaderno de elecciones del Consulado de Nueva España, 1636 a 1666. 
interviniera para cobrar al Consulado los adeudos del tercer cabezón alcabalatorio. Sin embargo, el visitador informó al virrey que, aun cuando el tribunal mercantil reconocía la deuda de 125.000 pesos, correspondiente al mencionado cabezón, se negaba a satisfacerla porque sus miembros no se consideraban responsables "de las deudas de sus antecesores" (Guice 1952: 80-82), ${ }^{56}$ los cuales pertenecían a la facción contraria al grupo que entonces se hallaba a la cabeza del la corporación. ${ }^{57}$

Ante la respuesta del prior y los cónsules, el virrey mandó hacer auditoría de los libros del Consulado correspondientes a los cabezones tercero y cuarto. Una vez que confirmó que los representantes del Consulado se negaban a satisfacer los alcances del tercer cabezón, el 15 de octubre, ordenó "secuestrar" los bienes del prior Jacinto Dávila Aguirre y los cónsules Felipe Navarro y Atienza y Diego de Serralde, a quienes mandó poner bajo arresto domiciliario (Guijo 1953: I, 236). La corporación mercantil respondió de inmediato con el pago de 40.000 pesos, el compromiso de entregar 20.000 pesos más en el término de 6 a 8 días, y 2.000 pesos anuales hasta saldar el adeudo (Guice 1952: 80-82; Israel 1980 [1975]: 254-255; Hoberman 1991: 212). El virrey aceptó dichas condiciones y posteriormente obtuvo la aprobación real, así como el encargo de cobrar el resto de la deuda. ${ }^{58}$

Todo parece indicar que el duque de Alburquerque estableció una alianza con Jacinto Dávila Aguirre y Felipe Navarro y Atienza. Luego de haber visto amenazados sus bienes y su libertad, dichos mercaderes

56 Dada la diferencia entre los 876.060 pesos que se había comprometido a pagar el Consulado por concepto de los adeudos del tercer cabezón, en 1644, y los 125.000 pesos mencionados, es muy probable que esta cifra sólo correspondiera a los últimos tres años del tercer cabezón, o que se hubiera realizado algún tipo de composición respecto al pago de la totalidad de la deuda.

57 Como vimos, el Consulado se hizo cargo del tercer cabezón de 1644 a 1646, años en los que fueron priores Domingo de Barainca (1644-45) y Simón de Haro (1646). En 1650, siendo prior Simón de Haro y cónsules Diego Rodríguez Félix y Jerónimo de Aramburu; Diego Millán, miembro de la facción que accedió a los cargos de representación en 1653, tuvo un conflicto con el Consulado porque se le exigió el pago de la alcabala, cuando dicho mercader alegó estar exento del gravamen por haber rematado el asiento de las Bulas de la Santa Cruzada (Guijo 1953, I: 130-131).

58 Mandamiento del virrey duque de Alburquerque, México, 7 de enero de 1656, AGNM, AHH, caja 664, exp. 3: Cuaderno de elecciones del Consulado de Nueva España, 1636 a 1666. 
pudieron haberse comprometido a pagar regularmente la renta de alcabalas y a satisfacer los adeudos del ramo, siempre que el virrey les asegurara el acceso a los cargos de representación corporativa. Esta hipótesis parece confirmarse por el hecho de que en 1654 fueron electos como prior Melchor de Terreros y como cónsul moderno Pedro de Eguren, quienes, al igual que el cónsul antiguo Diego Serralde, pertenecían al partido del que eran líderes el prior y el cónsul salientes.

Es posible que el Consulado volviera a incurrir en atrasos en el pago de la renta de alcabalas, o de los adeudos de la misma, ya que un año después la facción encabezada por Dávila Aguirre y Navarro y Atienza perdió el apoyo del duque de Alburquerque. En la reunión en que se habrían de elegir prior y cónsul para 1655 se leyó un documento en el que el virrey denunció las prácticas ocultas que llevaban a cabo ciertos líderes del Consulado con el objeto de que fueran nombrados sus candidatos. El duque expuso cómo "habiendo el Consulado [...] venido tres y cuatro veces a preguntarme qué mandaba o qué insinuaba acerca de la elección de prior y cónsules", había respondido que la decisión debía quedar a cargo de los electores. Y agregó, que aun cuando el arrendamiento de las alcabalas era una de las prioridades de la Real Hacienda, el virrey debía "guardarle al Consulado sus capitulaciones".

Alburquerque planteó que había elaborado el mencionado escrito con la intención de que

se descubra la malignidad y dañada intención que han tenido los que [...] quieren inquietar el comercio, alborotar las elecciones y reducirlas violentamente a lo que ellos desean por sus conveniencias.

$\mathrm{Y}$ advirtió que daría cuenta al rey para que

conozca las pasiones, intereses y dependencias llevadas de la malignidad [...] pues no sólo se han contentado, en levantar esta cizaña, sino por este camino quieren dar a entender algunos claramente que ha de dejar de ser aquel que ellos temen o que no les está bien por su gusto y conveniencias. $^{59}$

Del sufragio realizado en 1655 , sin la intervención del virrey, salieron electos prior Andrés del Rosal y cónsul Domingo de Cantabrana, el primero de los cuales no pertenecía a la facción que había pac-

59 Auto de las elecciones de prior y cónsul de 1655, AGNM, AHH, caja 664, exp. 32: Cuaderno de elecciones del Consulado de Nueva España, 1636 a 1666. 
tado con Alburquerque. ${ }^{60}$ Es muy probable que el prior Andrés del Rosal haya establecido compromisos con el grupo que había sido dirigido por Simón de Haro, ya que el año siguiente nuevamente hubo disputa por los cargos de representación del Consulado.

En 1656 el virrey modificó una vez más su posición respecto a las elecciones del cuerpo mercantil. Alburquerque remitió un mandamiento en el que destacó cómo la Real Hacienda había adquirido mayor importancia que nunca, debido a los "aprietos y gastos" generados por las guerras; situación que obligaba a que el cabezón alcabalatorio fuera manejado por "personas de toda satisfacción". En consecuencia, mandó que los electores sufragaran para el cargo de prior a alguna de las siguientes personas: Jacinto Dávila Aguirre, Felipe Navarro y Atienza, Diego Serralde, Juan Pedrique Montero o Juan Vázquez de Medina. ${ }^{61}$ Los tres primeros eran integrantes del bando que había pactado con el virrey el pago de las alcabalas, el cual aseguró que los electores designaran prior a Jacinto Dávila Aguirre y cónsul a Felipe Cervantes, quienes al igual que el cónsul antiguo, Domingo de Cantabrana, pertenecían al grupo mencionado. ${ }^{62}$ Todo parece indicar que esta facción sólo podía acceder a los cargos de representación cuando el virrey intervenía en las elecciones.

No tenemos noticia de que Alburquerque haya participado en los sufragios del Consulado en 1657. De modo que salieron electos prior Pedro López de Covarrubias ${ }^{63}$ y cónsul moderno Julián Diez de Posadas, ambos miembros del partido que había sido liderado por Simón de Haro. Sin embargo, la facción encabezada por Dávila Aguirre se resistió a perder el control del Consulado, así como la consiguiente gestión de las alcabalas, fenómeno que dio lugar a una seria disputa en torno a los sufragios de 1658 .

60 El cónsul antiguo, Pedro de Eguren, también era miembro de la facción mencionada.

61 Mandamiento del virrey duque de Alburquerque, México, 7 de enero de 1656 , AGNM, AHH, caja 664, exp. 32: Cuaderno de elecciones del Consulado de Nueva España, 1636 a 1666. A fines de 1655 el virrey aprovechó la muerte del exprior Simón de Haro para embargar sus bienes a fin de cubrir parte de los adeudos que aún mantenía el Consulado por concepto del tercer cabezón alcabalatorio (Guijo 1953, II: 40).

62 Auto de las elecciones de prior y cónsul de 1656, AGNM, AHH, caja 664 , exp. 32: Cuaderno de elecciones del Consulado de Nueva España, 1636 a 1666.

63 Dicho mercader había ocupado el mismo cargo en 1652. 
El 8 de enero, día en que se debía realizar la elección de prior y cónsul, no se presentaron los quince electores pertenecientes a la facción que dirigía Dávila Aguirre, ${ }^{64}$ muy probablemente debido a que no habían logrado el consenso respecto a sus candidatos. ${ }^{65}$ Nueve de los electores ausentes, encabezados por Jacinto Dávila Aguirre, Felipe Navarro Atienza y Domingo de Cantabrana, presentaron al duque de Alburquerque un memorial en el que denunciaron cómo en la asamblea en que habían sido sufragados los electores habían votado muchas personas que no cumplían con los requisitos señalados en las ordenanzas, porque tenían "tiendas y cajones en la plaza pública de esta ciudad, como son de tabaco, de miel, de especiería, cajoneros, loceros y roperos, y otros". Por tal motivo consideraron ilegítima dicha elección y solicitaron que se realizara nuevamente, con apego a la normatividad de la corporación. ${ }^{66}$

El virrey ordenó al tribunal mercantil que se oyera a los electores ausentes y se realizara la elección de prior y cónsul, de acuerdo con las ordenanzas de la corporación, "sin causar nulidad, ni hacer las causas". ${ }^{67}$ Luego de conocer el memorial del grupo disidente y el decreto del virrey, el juez de alzadas y el tribunal mercantil admitieron el nombramiento de los electores y mandaron proceder a la votación. No obstante, dicho auto fue apelado por los electores disconformes, de modo que Alburquerque ordenó que el asunto fuera determinado por los oidores.

64 Entre los quince electores que asistieron al Consulado, se encontraban el prior y los cónsules en funciones, al parecer, miembros de la facción disidente.

65 Los electores que no acudieron al Consulado eran Jacinto Dávila Aguirre, Melchor de Terreros, Felipe Navarro y Atienza, capitán Domingo de Cantabrana, Tiburcio de Urrea, Diego Millán, Juan Gallardo de Céspedes, Gregorio Pérez, Pedro de la Paz, Juan de Cabueñas, Cristóbal Jiménez, Fernando Cabeza de Vaca, Pedro de Eguren, Diego de Serralde y Simón de Soria. Los tres últimos habían avisado al portero del Consulado que estarían fuera de la ciudad, pero serían representados por Cristóbal Jiménez, Tiburcio de Urea y Juan Gallardo Céspedes, sin embargo, ninguno de éstos se presentó el día de la elección; además, no se consideró válida su excusa. Pedro González de Castañeda se excusó, junto con los primeros, pero finalmente se presentó a la elección.

66 Autos de las elecciones del Consulado de 1658, AGNM, AHH, caja 664, exp. 32: Cuaderno de elecciones del Consulado de Nueva España, 1636 a 1666. Los requisitos para pertenecer al Consulado pueden verse al inicio del artículo.

Decreto del duque de Alburquerque, México, 8 de enero de 1658, AGNM, AHH, caja 664, exp. 32: Cuaderno de elecciones del Consulado de Nueva España, 1636 a 1666. 
La Audiencia declaró nulos los comicios en que habían sido nombrados los electores, mandó que se repitiera "con los votos legítimos conforme a la ordenanza" y estableció una pena de 200 pesos para los electores que faltaran al sufragio de prior y cónsul. ${ }^{68}$ En la nueva elección fueron nombrados la mayor parte de los electores que habían sido designados en la primera ocasión, con excepción de ocho de los quince que habían acudido al Consulado el 8 de enero. Pero, los resultados de esta segunda elección volvieron a generar inconformidad, por lo que Alburquerque ordenó al juez de alzadas, al prior y a los cónsules que remediaran el problema con apego absoluto a las declaraciones de la Audiencia. ${ }^{69}$

El día de los comicios de prior y cónsul se había llegado a un acuerdo. La sesión dio inicio con la lectura de un nuevo despacho del virrey, en el que manifestó su deseo de que el Consulado eligiera con libertad a sus representantes, teniendo en cuenta que debían cumplir con el pago de las alcabalas. Alburquerque puso énfasis en dicho encargo en razón de que el prior saliente, Pedro López de Covarrubias, le había advertido acerca de la posibilidad de que hubiera un gran alcance en el ramo, debido a que habían llegado pocas mercancías de España, así como a los gastos ocasionados por la detención de la flota y "otros accidentes de la misma administración", ${ }^{70}$ muy probablemente con la intención de influir en el virrey respecto al nombramiento de los representantes de la corporación.

La forma en que fueron acaparados los cargos de representación por los electores disconformes a partir de 1658 (véase el cuadro número 2) parece indicar que salieron victoriosos de la contienda que enfrentaron. Vale la pena destacar que Felipe Navarro y Atienza fue electo prior el mismo año de 1658 y volvió a ocupar dicho oficio en $1661 .^{71}$ Juan de Cabueñas fue designado prior en 1665 , reelecto en 1666 y nombrado cónsul para el bienio 1660-61. Pedro de Eguren fue

68 Auto de la real Audiencia, México, 11 de enero de 1658, AGNM, AHH, caja 664, exp. 32: Cuaderno de elecciones del Consulado de Nueva España, 1636 a 1666.

69 Mandamiento del virrey duque de Alburquerque, México, 12 de enero de 1658, AGNM, AHH, caja 664, exp. 32: Cuaderno de elecciones del Consulado de Nueva España, 1636 a 1666.

70 Autos de las elecciones del Consulado de 1658, AGNM, AHH, caja 664, exp. 32: Cuaderno de elecciones del Consulado de Nueva España, 1636 a 1666.

71 Navarro y Atienza fue elector de manera consecutiva de 1650 a 1667. 
designado prior en 1660 , Felipe Cervantes en $1662^{72}$ y Tiburcio de Urrea en 1663. Este último, además, fue electo cónsul para el bienio 1658-59. ${ }^{73}$ Para el cargo de cónsul también fueron nombrados los siguientes miembros del mismo grupo: Cristóbal Jiménez (1662-63), Fernando Cabeza de Vaca (1663-64), Diego Millán (1664-65) y Simón de Soria (1665-66).

La mayoría de los electores que asistieron al Consulado para realizar las elecciones del 8 de enero de 1658 no volvieron a ocupar cargos de representación. Entre estos se destacan los mercaderes que habían fungido como priores o cónsules con anterioridad, quienes, muy probablemente, formaban parte de la facción que había dominado antes de 1653: Pedro López de Covarrubias, Jerónimo de Aramburu y Diego Rodríguez Félix. ${ }^{74}$ Es probable que dicho bando se hubiera debilitado a raíz de la muerte de Simón de Haro, acaecida en 1655, aun cuando López de Covarrubias había vuelto a ocupar el cargo de prior en 1657.

En 1658 el Consulado aún adeudaba a la Real Hacienda poco más de 54.000 pesos, correspondientes a los años de 1644 a 1646, en los que le habían subrogado el tercer cabezón alcabalatorio. ${ }^{75}$ El tribunal mercantil logró que el duque de Alburquerque rebajara la deuda a poco más de 48.800 pesos, de los cuales fueron saldados 33.700 pesos por los priores y cónsules que habían estado en funciones durante los años en que se había contraído el débito. ${ }^{76}$ De este modo, el compromiso se redujo a 15.120 pesos, monto que el virrey aceptó disminuir a 12.000 pesos, a condición de que pagaran 2.000 pesos anuales con los

72 Presumimos que Felipe Cervantes no pudo manifestarse con los electores disidentes, en razón de que ocupaba el cargo de cónsul. Este mercader fue nombrado diputado en 1660 y 1661, cargo que había ocupado en 1655 y había sido elector de 1652 a 1656 .

73 Urrea fue elector de 1642 a 1665 , durante 24 años consecutivos.

74 Tampoco volvieron a figurar en el Consulado, Mateo Delgado, Tomás Regil de la Sierra, Pedro Ruiz de la Colina y Francisco Sánchez de Cuenca, quienes sólo habían sido nombrados electores en 1658 .

75 Según los líderes del Consulado, de dicha cantidad, 40.129 pesos habían sido transferidos al ramo de avería y aproximadamente 13.600 pesos se habían destinado al pago de salarios y otros gastos relacionados con la recaudación de las alcabalas (Guice 1952: 54, 56, 82).

76 Domingo de Barainca había ocupado el cargo de prior en 1644 y 1645 , y Simón de Haro en 1646, y en los mismos años habían sido cónsules Bernardo de Cuéllar, Pedro de Soto López, Andrés del Rosal y Melchor de Terreros. 
productos del derecho de avería, a partir de 1659 (Guice 1952: 56-57, 82-83; Hoberman 1991: 212). ${ }^{77}$

En octubre de 1658, una vez que el Consulado demostró que podía asegurar el pago de la renta de alcabalas y de los adeudos correspondientes, Alburquerque lo autorizó a rendir únicamente el ajuste de cuentas correspondiente a los doce años que habían corrido del cuarto cabezón alcabalatorio, en lugar de hacer un recuento detallado de las mismas, debido a las supuestas dificultades que enfrentaban los contadores del Consulado para hacer concordar su contabilidad con la del Tribunal de Cuentas. En compensación, la corporación mercantil pagó de inmediato 24.000 pesos, a cuenta de la deuda del cuarto cabezón, y se comprometió a continuar con el pago del mismo. Además, los miembros del tribunal mercantil solicitaron al rey que el duque de Alburquerque continuara en el gobierno de la Nueva España. ${ }^{78}$

En las elecciones de 1659, el duque remitió al Consulado un mandamiento en el que planteó que correspondía al prior, los cónsules y los electores nombrar a las personas más apropiadas para la corporación y la administración de las alcabalas, decisión que, según dijo, había hecho saber a los primeros en las tres ocasiones en que lo habían consultado ${ }^{79}$ Un año después, el virrey recurrió al juez de alzadas para dar a conocer la misma posición acerca de los comicios. En esta forma, Alburquerque manifestó su decisión de que las elecciones fueran dirigidas, como una forma de garantizar que se mantuviera a la cabeza del Consulado la facción que había acordado el pago de la renta de alcabalas y parte de sus deudas.

En enero de 1661 había asumido el gobierno de la Nueva España el marqués conde de Baños, quien, a petición de los dirigentes del Consulado, intervino en sus elecciones. Al igual que su antecesor, el nuevo virrey brindó su apoyo al grupo que se había comprometido a satisfacer la renta de alcabalas. El virrey mandó que se eligiera prior a

77 La avería era un gravamen que se imponía a las mercancías que entraban y salían por mar de la Nueva España, el cual había sido introducido a raíz de la creación del Consulado para destinar sus productos al sostenimiento de la corporación (Valle Pavón 1997: 44-48).

78 Del Consulado a Su Majestad agradeciendo las mercedes que le ha hecho el virrey duque de Alburquerque, México, 8 de octubre de 1659, AGI, Méx., leg. 322. AGNM, AHH, caja 664, exp. 32: Cuaderno de elecciones del Consulado de Nueva España, 1636 a 1666. 
la persona más conveniente para negociar el quinto cabezón alcabalatorio y dar fin al cuarto "con ajustamiento y paga", y precisó que se debía votar por un sujeto que hubiera desempeñado el cargo de prior con anterioridad. Además, ordenó que el cónsul Pedro Sedano continuara en el oficio dos años más, porque había pagado las alcabalas con puntualidad y tratado a "los comerciantes de España, dentro y fuera de México con blandura y sin queja". 80 En consecuencia, se volvió a elegir a Felipe Navarro y Atienza, en tanto que Pedro Sedano permaneció en el cargo de cónsul dicho año y el siguiente, permaneciendo en el oficio cuatro años consecutivos.

Al parecer el virrey tomó una decisión acertada, ya que la facción a la que pertenecían dichos mercaderes cubrió las rentas de los años en los que tuvo a su cargo el cuarto cabezón alcabalatorio, si bien enfrentó ciertas dificultades. En 1661, el Consulado no logró satisfacer el último entero de la renta del mencionado cabezón. En enero de 1662 resolvió hacer el repartimiento de la cantidad que faltaba en otro momento, ante "la imposibilidad que se resentía en los vecinos" para poder conseguir el dinero. ${ }^{81}$ Unos meses después, los individuos que habían sido priores y cónsules en 1660, 1661 y 1662, acordaron prestar mil pesos cada uno para pagar el adeudo, mientras se determinaba el pleito que tenía el Consulado con el Consejo de Indias, en relación con el cuarto cabezón o se realizaba el repartimiento entre los mercaderes.

A mediados de 1663, el prior Tiburcio de Urrea, los ex-priores Pedro de Eguren, Felipe Navarro y Felipe de Cervantes, y los ex-cónsules Pedro Sedano, Juan de Cabueñas y Cristóbal Jiménez ${ }^{82}$ entregaron siete mil pesos al receptor del ramo de alcabalas, a razón de mil pesos cada uno. ${ }^{83}$ De este modo, el grupo que había negociado con la autori-

80 Orden y decreto del marqués conde de Baños, México, 7 de enero de 1661, AGNM, AHH, caja 664, exp. 32: Cuaderno de elecciones del Consulado de Nueva España, 1636 a 1666.

81 Autos correspondientes a la negativa de Julián Posadas a contribuir con el préstamo para el entero de la renta de alcabalas, México, 9 de agosto de 1663, AGNM, AHH, caja 664, exp. 32: Cuaderno de elecciones del Consulado de Nueva España, 1636 a 1666.

82 Urrea, además, había sido diputado en 1661 y 1662.

83 Sólo quedó pendiente el pago de los mil pesos correspondientes a Julián Díaz de Posadas, quien había sido cónsul en el bienio $1657-58$ y diputado en 1660 y 1661, y que se negó a cumplir con el compromiso que había contraído, con el ar- 
dad virreinal el pago de la renta y había obtenido su apoyo para permanecer en los cargos de representación del Consulado, cumplió con su compromiso de pagar las rentas de los años en los que estuvo a cargo del cuarto cabezón alcabalatorio. Sin embargo, dicha facción no saldó el adeudo correspondiente a los primeros años de dicho encabezamiento. $^{84}$

El Cabildo de la ciudad se hizo cargo del quinto cabezón alcabalatorio, que debía correr de 1662 a 1676, al parecer, por el interés del conde de Baños en favorecer a sus miembros (Valle Pavón 1997: 8688). Sin embargo, dicha administración quebró una vez más, muy probablemente debido a la resistencia de los miembros del Consulado a pagar el gravamen. La corporación mercantil asumió una vez más la gestión de la renta de 1673 a 1676, y volvieron a presentarse conflictos por los cargos de representación.

En octubre de 1674 se mandó sacar copia de los autos que se habían dictado en relación con los sufragios de 1653, probablemente para tener conocimiento del modo en que se había resuelto la disputa que entonces se había presentado en la cúpula del Consulado. Todo indica que el interés por mantener en la cabeza del Consulado a la facción con la que se había negociado el pago de la renta de alcabalas, dio lugar a la modificación de su normatividad electoral, la cual aparece transformada en la Recopilación de Leyes de los Reynos de Indias de 1681 .

En las reglas sobre los comicios contenidas en la Recopilación la participación de la asamblea de mercaderes fue drásticamente restringida. En adelante quedó a cargo del prior y el cónsul salientes, y del cónsul que pasaba de moderno a antiguo, la prerrogativa de seleccionar a los electores. La lista de los "candidatos" a electores, elaborada por las autoridades mencionadas, debía ser entregada a los mercaderes que asistían a la asamblea electoral, quienes debían jurar que elegirían a los individuos "más convenientes para Electores", aun cuando no

gumento de que no tenía la obligación de hacerlo, ya que había dejado de pertenecer la corporación mercantil; Autos correspondientes a la negativa de Julián Posadas a contribuir con el préstamo para el entero de la renta de alcabalas, México, 9 de agosto de 1663, AGNM, AHH, caja 664, exp. 32: Cuaderno de elecciones del Consulado de Nueva España, 1636 a 1666.

84 El 17 de marzo de 1663 el virrey notificó al Consulado que debía entrar a las cajas reales 200.000 pesos, suma que probablemente correspondía a las deudas del cuarto cabezón (Guijo 1953: 192-193). 
podían separarse de las opciones señaladas. ${ }^{85}$ En esta forma, el privilegio de designar a los electores fue transferido de la asamblea de mercaderes al prior y los cónsules.

De las leyes contenidas en la Recopilación se desprende cómo, para elaborar la lista de electores, el prior y los cónsules debían negociar y establecer compromisos que permitieran llegar a acuerdos previos con los principales grupos de interés que se disputaban el poder al interior del Consulado. La modificación de las ordenanzas en materia electoral, dejó la decisión acerca de las nominaciones para los empleos de electores a cargo de un pequeño sector de la oligarquía mercantil, el cual, muy probablemente, aseguraba de antemano quienes debían ser nombrados prior y cónsul. De este modo se pretendió acabar con las disputas sobre la designación de los cargos de representación del Consulado. ${ }^{86}$

En adelante, la discusión sobre las designaciones para los cargos de prior y cónsul se trasladó al ámbito privado; fenómeno que probablemente influyó en la división de los miembros del Consulado en los partidos de vizcaínos y montañeses. ${ }^{87}$ Este supuesto parte del hecho de que fue en 1681 cuando los mercaderes procedentes de las provincias de Navarra, Vizcaya, Álava y Guipúzcoa crearon la Cofradía de Nuestra Señora de Aránzazu (García-Ayluardo 1983), en tanto que los individuos de origen santanderino pudieron haber establecido la Congregación del Santo Cristo de Burgos en una fecha cercana. ${ }^{88}$ Ambas cofradías debieron haber favorecido la organización de los partidos mencionados, además de fortalecer los vínculos entre sus miembros a

85 Recopilación 1987 [1681]: libro 9, título 46, ley 6. La transformación introducida respecto a las ordenanzas del Consulado no se registra en la Recopilación, al margen de la ley modificada se refiere como fuente las ordenanzas núm. iiii, que había sido aprobada por Felipe III, a pesar de las diferencias entre ambas leyes.

86 La modificación de la normatividad electoral del Consulado no puso fin a la competencia por los cargos de prior y cónsul, como puede verse en el artículo que presenta Hausberger en esta misma publicación.

87 Una parte importante de los miembros del Consulado debieron haber sido originarios de las provincias mencionadas, no obstante, dichas parcialidades también pudieron haber incluido mercaderes criollos y procedentes de otras provincias de la península, como sucedía hacia mediados del siglo XVIII (Borchart de Moreno 1984 [1976]: 30-32).

88 No se conoce la fecha de fundación de la Congregación del Cristo de Burgos (Luque 1995: 42-45, y 1998: 93-94). 
través de la confraternidad étnica, la solidaridad y la confianza mutua. $^{89}$

\section{Consideraciones finales}

El análisis de los procedimientos para acceder a los cargos de representación del Consulado y de los cambios que éstos presentaron hacia el tercer cuarto del siglo XVII, nos permitió empezar a conocer las formas de negociación política que se daban al interior de la corporación y con la autoridad virreinal, los mecanismos de reemplazo de las facciones dominantes y el grado de autonomía que tenía el Consulado respecto a los representantes de la Corona.

El interés de los mercaderes que encontraban en la cúpula del Consulado en obtener beneficios de su participación en la gestión del derecho de alcabalas, dio lugar a la competencia por los cargos de prior y cónsul, así como a la formación de partidos. Los conflictos que se desataron por la dirigencia de la corporación pusieron de manifiesto la intervención del virrey en los sufragios del Consulado. No sabemos desde cuándo se consultaba a los virreyes acerca de la designación de los candidatos para ocupar los cargos de representación corporativa, sin embargo, hemos constatado cómo la administración de la renta de alcabalas por parte del Consulado legitimó a la autoridad virreinal para intervenir en sus elecciones.

Las disputas electorales que se presentaron en el Consulado, poco después de que se hiciera cargo la gestión del derecho de alcabala por su propia cuenta, mostraron la imposibilidad de manipular a la asamblea integrada por la universidad de mercaderes, así como la consiguiente necesidad de ejercer mayor control sobre los comicios. Para la autoridad real, y para la facción que adquirió el dominio de la corporación mercantil al garantizar el pago de la renta de alcabalas, se hizo evidente que el medio para asegurar las nominaciones a los cargos de representación, radicaba en adquirir dominio pleno sobre la designación de los electores. En consecuencia, se modificaron las ordenanzas del Consulado, de tal manera que quedó en manos del prior y los cónsules el nombramiento de los electores. A partir de entonces, las nego-

89 María Teresa Huerta (1997: 78-80) mostró la compleja red de relaciones que integraron los mercaderes de origen vizcaíno en la década de 1680, la cual les permitió fortalecer su posición en los mercados minero y filipino. 
ciaciones relativas a la nominación de los sujetos que encabezarían la corporación se trasladaron al ámbito de lo privado, fenómeno que, al parecer, dio lugar a la división de la universidad de mercaderes en los partidos de vizcaínos y montañeses.

En un futuro sería conveniente profundizar en el estudio de los dos grupos que detentaron la representación del Consulado hacia mediados del siglo XVII, a fin de averiguar qué lazos los unían, la forma en que se redistribuyeron los miembros de la élite entre ambas facciones, así como las relaciones que sostenían sus líderes con los virreyes y los miembros de la Audiencia. Asimismo, valdría la pena estudiar la forma en que se llevaban a cabo los repartimientos de la renta de alcabalas, con el objeto de conocer mejor los mecanismos de que se valieron los dirigentes del Consulado para beneficiarse con descuentos en el pago del gravamen. 